\title{
Espaço físico, espaço social e espaço físico apropriado ${ }^{1}$
}

\author{
PIERRE BoURdieU
}



SOCIOLOGIA deve atentar para o fato de que os seres humanos são, simultaneamente, indivíduos biológicos e agentes sociais que são constituídos como tais na e pela relação com o espaço social, ou melhor, com campos. Enquanto corpos e indivíduos biológicos, eles estão, assim como as coisas, situados em um lugar (eles não são dotados da ubiquidade física que lhes permitiria estar em vários lugares ao mesmo tempo), e ocupam um local. ${ }^{2} \mathrm{O}$ lugar, topos, pode ser definido absolutamente como o sítio em que um agente ou uma coisa se situam, "têm lugar", existem, enfim, como localização; ou, relativamente, relacionalmente, como posição, escalão no interior de uma ordem. O local ocupado pode ser definido como a extensão, a superfície e o volume que um agente ou uma coisa ocupa; suas dimensões, ou melhor, suas medidas externas ${ }^{3}$ (como se diz, às vezes, de um veículo ou de um móvel).

Como o espaço físico é definido pela exterioridade recíproca das partes, o espaço social é definido pela exclusão mútua (ou distinção) das posições que o constituem; isto é, como estrutura de justaposição de posições sociais. Os agentes sociais, e também as coisas - do modo como elas são apropriadas pelos agentes, e, portanto, constituídas como propriedades -, situam-se em um lugar do espaço social que pode ser caracterizado por sua posição relativa quanto aos outros lugares (acima, abaixo, entre etc.); e pela distância que o separa deles.

Com efeito, o espaço social tende a se retraduzir, de maneira mais ou menos rigorosa, no espaço físico sob a forma de um determinado arranjo distributivo dos agentes e das propriedades. Consequentemente, todas as distinções propostas em relação ao espaço físico residem no espaço social reificado (ou, o que dá no mesmo, no espaço físico apropriado), que é definido - para falar como Leibniz - pela correspondência entre uma determinada ordem de coexistência dos agentes e uma determinada ordem de coexistência das propriedades. ${ }^{4}$ Cada agente se caracteriza pelo lugar em que está situado de maneira mais ou menos permanente: o domicílio (aquele do qual se diz que é "sem eira nem beira" 5 ou "sem domicílio fixo" não tem - quase - existência social); e ele se caracteriza pela posição relativa que suas localizações temporárias (por exemplo os locais de honra, posicionamentos regrados pelo protocolo) e, sobretudo, permanentes (endereço privado e endereço profissional) ocupam em relação às localizações dos outros agentes. Ele caracteriza-se também pela posição que ocupa (juridicamente) no espaço, através de suas propriedades (casas, apartamentos ou escritórios, 
terras para cultivar, explorar ou construir etc.), que são mais ou menos espaçosas ou, como se diz às vezes, "space consuming" (a ostentação do espaço apropriado sendo uma das formas por excelência da ostentação do poder). Consequentemente, o lugar e o local ocupados por um agente no espaço físico apropriado constituem excelentes indicadores de sua posição no espaço social. É preciso notar, de passagem, que uma parte da inércia das estruturas constitutivas do espaço social resulta do fato de que elas estão inscritas no espaço físico, e só podem ser modificadas à custa de um trabalho de transplantação, de uma mudança das coisas, e de um desenraizamento ou de uma deportação das pessoas - operações necessariamente custosas.

A estrutura do espaço social se manifesta assim, nos mais diversos contextos, sob a forma de oposições espaciais, o espaço habitado (ou apropriado) funcionando como uma espécie de metáfora espontânea do espaço social. Em uma sociedade hierarquizada, não existe espaço que não seja hierarquizado e que não exprima as hierarquias e as diferenças sociais de um modo deformado (mais ou menos) e, sobretudo, mascarado pelo efeito de naturalização acarretado pela inscrição durável das realidades sociais no mundo físico: diferenças produzidas pela lógica social podem, assim, parecer emergidas da natureza das coisas (basta pensar na ideia de "fronteira natural").

Assim, a divisão em duas partes do espaço interno da casa kabyle-por mim já analisada detalhadamente ${ }^{6}$ - constitui, sem dúvida, o paradigma de todas as divisões em lugares separados (na igreja, na escola, nos lugares públicos e na própria casa) nas quais se retraduzia e ainda se retraduz, embora de modo cada vez mais discreto, a estrutura da divisão do trabalho entre os sexos. Mas, da mesma forma, poderíamos analisar a estrutura do espaço escolar, que, em suas diversas variantes, tende sempre a marcar o local eminente do professor (a cátedra); ou a estrutura do espaço urbano: assim, por exemplo, o espaço parisiense apresenta, além da retradução principal das diferenças econômicas e culturais na distribuição espacial das habitações entre os bairros centrais e os bairros periféricos e os subúrbios, uma oposição secundária, mas bem marcada, entre a "margem direita" e a "margem esquerda", a qual corresponde à divisão fundamental do campo do poder entre, grosso modo, a arte e os negócios.

Vê-se aí o exemplo de uma divisão social objetivada no espaço físico, que, como já apontei alhures, funciona simultaneamente como princípio de visão e de divisão, como categoria de percepção e de apreciação; em suma, como estrutura mental (a casa kabyle foi outro exemplo disso). E pode-se pensar que estruturas do espaço físico apropriado constituem uma das mediações através das quais as estruturas sociais se convertem em sistemas de preferências e em estruturas mentais. Mais precisamente, a inscrição imperceptível, nos corpos, das estruturas da ordem social ocorre certamente, em grande parte, através dos deslocamentos e dos movimentos do corpo, das poses e das posturas corporais que essas estruturas sociais convertidas em estruturas espaciais organizam e qualificam socialmente 
como ascensão ou declínio, entrada (inclusão) ou saída (exclusão), aproximação ou distanciamento em relação a um lugar central e valorizado (basta pensar na metáfora do "fogão", ponto dominante da casa kabyle, que Halbwachs retomou com naturalidade para falar do "foco dos valores culturais" 8 ): penso, por exemplo, no porte respeitoso que evocam o tamanho e a altura (aqueles do monumento, do pódio ou da tribuna) ou, ainda, a frontalidade das obras esculturais ou pictóricas; ou, mais sutilmente, penso em todas as atitudes de deferência e de reverência que a simples qualificação social do espaço (locais de honra, a primeira fila etc.) e todas as hierarquizações práticas das regiões do espaço (parte alta/ parte baixa, parte nobre/parte vergonhosa, proscênio/bastidores, fachada/depósito, lado direito/lado esquerdo etc.) tacitamente impõem.

O espaço apropriado é um dos lugares onde o poder se afirma e se exerce, e provavelmente sob a forma mais sutil, a da violência simbólica como violência despercebida: os espaços arquitetônicos - cujas injunções mudas se dirigem diretamente ao corpo, obtendo deste, tão certamente quanto a etiqueta das sociedades de corte, a reverência, o respeito que, como diz o latim, nasce do distanciamento (e longinquo reverentia); ou melhor, do estar longe, a distância respeitosa - são sem dúvida os componentes mais importantes da simbologia do poder, em razão mesmo de sua invisibilidade (até para os próprios analistas, geralmente ligados, como os historiadores após Schramm, aos símbolos mais visíveis, cetros e coroas $^{9}$ ).

O espaço social se encontra assim inscrito simultaneamente na objetividade das estruturas espaciais e nas estruturas subjetivas que são, em parte, o produto da incorporação dessas estruturas objetivadas. É desse modo que, como já apontei, a oposição entre a "margem esquerda" do Sena (hoje praticamente estendida aos subúrbios) e a margem direita - que os mapas e as análises estatísticas (dos públicos para os teatros; ou das características dos artistas expostos para as galerias) tornam evidente - está presente "na cabeça" dos espectadores potenciais, mas também dos autores teatrais ou dos pintores e dos críticos sob a forma da oposição, que funciona como uma categoria de percepção e de apreciação, entre o teatro de vanguarda, de pesquisa, e o teatro de bulevar, conformista, repetitivo; entre o público jovem e o público idoso e burguês, ou ainda entre o cinema de arte e experimental e as salas exclusivas etc.

Nada é mais difícil, vê-se, do que sair do espaço social reificado a fim de pensá-lo, sobretudo em sua diferença em relação ao espaço social. E isso tanto mais pelo fato de que o espaço social é, enquanto tal, predisposto a se deixar visualizar sob a forma de esquemas espaciais, e porque a linguagem mais comumente utilizada para falar disso é carregada de metáforas emprestadas do espaço físico.

\section{1) Espaço físico e espaço social}

É preciso, portanto, começar estabelecendo uma distinção clara entre o espaço físico e o espaço social para, em seguida, indagar-se como e em quê a localização em um ponto (inseparável de um ponto de vista) do espaço físico (e 
a presença no referido ponto) pode afetar a representação que os agentes têm de sua posição no espaço social e, portanto, de sua própria prática.

O espaço social não é o espaço físico, mas ele tende a se realizar de forma mais ou menos completa e exata nesse espaço. O que explica que tenhamos tanta dificuldade de pensá-lo enquanto tal, em estado separado. O espaço, tal como nós o habitamos e como o conhecemos, é socialmente marcado e construído. O espaço físico só pode ser pensado como tal por meio de uma abstração (geografia física); ou seja, ignorando-se decididamente tudo o que ele deve ao fato de ser um espaço habitado e apropriado, isto é, uma construção social e uma projeção do espaço social, uma estrutura social em estado objetivado (por exemplo, a casa kabyle ou a planta de uma cidade), a objetivação e a naturalização de relações sociais passadas e presentes.

O espaço social, espaço abstrato constituído pelo conjunto dos subespaços ou dos campos (campo econômico, campo intelectual etc.), dos quais cada um deve sua estrutura à distribuição desigual de uma espécie particular de capital, pode ser apreendido sob a forma da estrutura da distribuição das diferentes espécies de capital que funcionam, simultaneamente, como instrumentos e objetos de lutas no conjunto dos campos (o que, em $A$ Distinção, é designado como volume global e estrutura do capital ${ }^{10}$ ). O espaço social fisicamente realizado (ou objetivado) se apresenta como distribuição, no espaço físico, de diferentes espécies de bens e serviços e também de agentes individuais e grupos fisicamente localizados (enquanto corpos ligados a um lugar permanente: domicílio fixo ou residência principal) e dotados de oportunidades de apropriação desses bens e serviços mais ou menos importantes (em função de seu capital, e também da distância física em relação a esses bens, a qual também depende de seu capital). É essa dupla distribuição no espaço dos agentes enquanto indivíduos biológicos, e dos bens, que define o valor diferencial das diversas regiões do espaço social realizado.

As distribuições no espaço físico dos bens e serviços correspondendo aos diferentes campos, ou, se preferirmos, os diferentes espaços sociais fisicamente objetivados, tendem a se sobrepor, pelo menos grosseiramente: resultam daí concentrações dos bens mais raros e de seus proprietários em determinados lugares do espaço físico (Fifth Avenue, Rue du Faubourg Saint-Honoré), que se opõem assim, sob todos os aspectos, aos lugares que agrupam principalmente, e às vezes exclusivamente, os mais desprovidos (guetos). Tais lugares constituem armadilhas para o analista em relação ao fato de que, aceitando-os como tais, o observador imprudente (como aquele que tenta analisar a simbólica que é característica dos comércios de luxo da Madison Avenue e da Fifth Avenue, o uso de nomes próprios ou comuns emprestados do francês, o emprego de duplos nobres dos nomes usuais de profissões, a evocação da antiguidade etc.) condena-se a uma abordagem substancialista e realista, que deixa escapar o essencial: assim como a Madison Avenue, a Rue du Faubourg Saint-Honoré reúne negociantes de quadros, antiquários, casas de alta costura, calçadistas, pintores, decoradores 
etc.; ou seja, todo um conjunto de comércios que têm em comum o fato de ocuparem posições elevadas (portanto, homólogas entre si) em seus campos (ou espaços sociais) respectivos, e que só podem ser compreendidos naquilo que têm de mais específico, a começar por seus nomes, em relação com os comércios pertencentes ao mesmo campo, mas situados em outras regiões do espaço parisiense. Por exemplo, os decoradores da Rue du Faubourg Saint-Honoré se opõem (e primeiramente por seu nome nobre, mas também por todas as suas características, natureza, qualidade e preço dos produtos oferecidos, qualidade social da clientela etc.) àqueles que, no Faubourg Saint-Antoine, chamamos de marceneiros; os hairdressers estabelecem uma relação homóloga com os simples cabeleireiros, os calçadistas com os sapateiros etc. Assim, na medida que apenas concentra os pólos positivos de todos os campos (como o gueto concentra todos os pólos negativos), esse espaço não tem em si mesmo sua verdade. $\mathrm{O}$ mesmo ocorre com a capital, que, ao menos no caso da França, é, sem jogo de palavras, o lugar do capital; isto é, o lugar do espaço físico onde estão concentrados os ápices de todos os campos e a maioria dos agentes que ocupam essas posições dominantes. Ela só pode ser, portanto, pensada adequadamente em relação à província, que não é nada além da privação (relativa) da capital e do capital.

\section{2) A gênese da estrutura do espaço físico apropriado}

O espaço ou, mais precisamente, os lugares e as posições do espaço social reificado ou do espaço físico apropriado, devem a sua raridade e o seu valor ao fato de serem um dos objetos de lutas de que os diferentes campos são o lugar, na medida que marcam ou asseguram uma vantagem mais ou menos decisiva nessas lutas.

A capacidade de dominar o espaço apropriado, notadamente apropriando-se (material ou simbolicamente) dos bens raros (públicos ou privados) que aí se encontram distribuídos, depende do capital possuído. O capital permite manter a distância pessoas e coisas indesejáveis e, ao mesmo tempo, aproximar-se das pessoas e coisas desejáveis, minimizando assim o dispêndio (notadamente de tempo) necessário para delas se apropriar. Inversamente, aqueles que são desprovidos de capital são mantidos à distância, seja física ou simbolicamente, dos bens socialmente mais raros, e condenados a conviver com as pessoas ou bens mais indesejáveis e menos raros. A ausência de capital leva ao seu paroxismo a experiência da finitude: ela acorrenta a um lugar. Inversamente, a posse do capital garante, além da proximidade física (residência) em relação aos bens raros, a quase ubiquidade que torna possível o domínio econômico e simbólico dos meios de transporte e de comunicação (e que é frequentemente redobrado pelo efeito da delegação, poder de existir e de agir à distância por interposta pessoa).

Resulta daí que a estrutura da distribuição espacial dos poderes, isto é, das propriedades durável e legitimamente apropriadas e dos agentes com oportunidades desiguais de acesso ou de apropriação material ou simbólica (oportunidades que, conforme se viu, definem-se na relação entre a distribuição espacial dos 
agentes - definidos inseparavelmente como corpos localizados e como detentores de capital - e a distribuição dos bens ou serviços socialmente disponíveis), representa a forma objetivada de um estado das lutas sociais pelo que se pode denominar os lucros do espaço.

Essas lutas podem assumir uma forma individual: a mobilidade espacial, intra ou intergeracional - os deslocamentos nos dois sentidos entre a capital e a província, por exemplo, ou os endereços sucessivos no interior do espaço hierarquizado da capital -, constitui um bom indicador dos êxitos ou fracassos obtidos nessas lutas e, mais amplamente, de toda a trajetória social (desde que se considere que, do mesmo modo como agentes de idades e trajetórias sociais diferentes, altos quadros jovens e quadros médios mais velhos, por exemplo, podem coexistir temporariamente nos mesmos postos de trabalho, eles podem reencontrar-se, também temporariamente, em lugares de residência vizinhos).

As lutas pelo espaço também podem se realizar em escala coletiva, através notadamente das lutas políticas que se desenrolam desde o nível nacional, com as políticas habitacionais, até o nível municipal, notadamente através da construção e atribuição de moradias sociais ou das escolhas em termos de equipamentos públicos: elas têm efetivamente como objeto a construção de grupos homogêneos de base espacial; ou seja, uma segregação social que é simultaneamente causa e efeito da posse exclusiva de um espaço e dos equipamentos necessários ao grupo que o ocupa, e à sua reprodução. (A dominação do espaço é uma das formas privilegiadas do exercício da dominação, e a manipulação da distribuição dos grupos no espaço foi sempre colocada a serviço da manipulação dos grupos pensa-se aqui particularmente nos usos do espaço pelas diferentes formas de colonização.)

Os lucros espaciais podem assumir a forma de lucros de localização, eles mesmos passíveis de serem analisados em duas classes: as rendas de situação, que são associadas ao fato de se estar situado perto de coisas (bens ou serviços tais como os equipamentos educativos, culturais ou sanitários) e de agentes (uma determinada vizinhança implicando lucros de tranquilidade, de segurança etc.) raros e desejáveis, ou longe de bens ou de agentes indesejáveis; os lucros de posição ou de gradação (como os que são assegurados por um endereço prestigioso), caso particular dos lucros simbólicos de distinção que são associados à posse monopolista de uma propriedade distintiva. (As distâncias físicas podendo ser medidas segundo uma métrica espacial ou, melhor, segundo uma métrica temporal - na medida que os deslocamentos tomam um tempo mais ou menos longo, conforme as possibilidades de acesso a meios de transporte, públicos ou privados -, e o poder que o capital, sob suas diferentes formas, confere ao espaço é também, simultaneamente, um poder sobre o tempo). Os lucros espaciais podem assumir também a forma de lucros de ocupação (ou de medidas externas), a posse de um espaço físico (parques vastos, apartamentos amplos etc.) podendo ser uma maneira de manter a distância toda espécie de intrusão indesejável (es- 
sas são as "risonhas perspectivas" do solar inglês que, como observa Raymond Williams, em $O$ campo e a cidade, transformam o campo e seus camponeses em paisagem, para o prazer do proprietário $;{ }^{11}$ ou as "vistas irretocáveis" das publicidades imobiliárias). Uma das vantagens que proporciona o poder sobre o espaço é a possibilidade de colocar a distância (física) coisas ou pessoas que incomodam e colocam em descrédito os agentes, notadamente ao impor a colisão, vivida como promiscuidade, de maneiras de ser e de fazer socialmente incompatíveis; ou mesmo ao invadir o espaço percebido, visual ou auditivo, com espetáculos ou ruídos que, por serem socialmente marcados e negativamente conotados, estão fadados a ser percebidos como intrusões ou mesmo agressões.

Um habitat, como lugar físico socialmente qualificado, oferece oportunidades médias de apropriação dos diversos bens e serviços materiais ou culturais disponíveis em um dado momento. Tais oportunidades se especificam para os diferentes ocupantes desse habitat segundo as capacidades de apropriação (materiais - dinheiro, meios de transporte privados etc. - e culturais) de cada agente (uma doméstica espanhola do XVI arrondissement de Paris $^{12}$ não tem as mesmas oportunidades de se apropriar dos bens e serviços ali ofertados que tem a sua patroa). Pode-se ocupar fisicamente um habitat sem habitá-lo, propriamente falando, se não se dispõe dos meios tacitamente exigidos, a começar por um determinado habitus. Este é o caso dessas famílias argelinas que, ao passar de um bairro miserável ${ }^{13}$ para uma cité $H L M,{ }^{14}$ sentiam-se inesperadamente "superadas" por sua nova habitação, tão longamente aguardada, por não poderem cumprir as exigências que essa implicitamente comportava: os meios financeiros indispensáveis para cobrir os novos custos infligidos (em termos de consumo, de gás e de eletricidade, mas também de transporte, de instalação etc.); e também todo o estilo de vida, feminino, notadamente, que se encontrava indiretamente inscrito em um espaço aparentemente universal, desde a necessidade e a arte de fabricar cortinas até a aptidão de viver livremente em um meio social de desconhecidos.

Em suma, se o habitat contribui para fazer o habitus, o habitus contribui também para fazer o habitat, através dos usos sociais, mais ou menos adequados, que ele inclina os agentes a fazer desse mesmo habitat. É-se assim levado a duvidar da crença de que a aproximação espacial ou, mais exatamente, a coabitação de agentes muito distanciados no espaço social pode, em si, ter um efeito de reaproximação social ou, preferindo-se, de dessegregação: com efeito, nada é mais distante e intolerável do que pessoas socialmente distantes que se encontram próximas no espaço físico. E também é preciso questionar a ignorância (passiva ou ativa) das estruturas sociais do espaço habitado e das estruturas mentais de seus habitantes presumidos, que leva tantos arquitetos a fazer como se estivessem em condições de impor o uso social de construções e equipamentos nos quais projetam suas estruturas mentais; isto é, as estruturas sociais das quais essas estruturas são o produto. 
Pode-se considerar a experiência limite das famílias que são e se sentem deslocadas no espaço que lhes é concedido, como paradigma da experiência à qual se é exposto todas as vezes em que se entra em um espaço sem preencher todas as condições que ele exige tacitamente de seus ocupantes. Isso pode ser a posse de um certo capital cultural, direito de entrada verdadeiro que pode interditar a apropriação real dos bens ditos públicos ou a intenção mesma de apropriar-se deles. Pensa-se aqui evidentemente nos museus, mas isso vale também para serviços mantidos espontaneamente, por mais universalmente necessários que sejam, como os das instituições médicas ou jurídicas, ou mesmo os serviços oferecidos pelas instituições destinadas a favorecer o acesso àquelas, como a seguridade social ou as diferentes formas de assistência gratuita. Tem-se a Paris de seu capital econômico, mas também de seu capital cultural e de seu capital social: não basta entrar no Beaubourg ${ }^{15}$ para se apropriar do museu de arte moderna; e nem é mesmo certeza de que seja preciso e baste entrar nas salas consagradas à arte moderna (o que nem todos evidentemente fazem) para descobrir que não é suficiente entrar aí para delas se apropriar...

Além do capital econômico e do capital cultural, alguns espaços, e particularmente os mais fechados, os mais "seletos", também requerem capital social. Tais espaços só podem proporcionar capital social, e ainda capital simbólico - e isso pelo efeito de clube, que resulta do ajuntamento durável, no interior do mesmo espaço (aquele dos bairros chiques ou das residências de luxo), de pessoas e coisas que se assemelham naquilo em que são diferentes da grande maioria, no fato de que têm em comum o fato de não serem comuns -, na medida em que excluem juridicamente (por uma forma mais ou menos afixada de numerus clansus) ou de fato (estando o intruso condenado a uma espécie de exclusão interior própria a privá-lo de alguns dos lucros de pertencimento) todos aqueles que não apresentam todas as propriedades desejadas, ou que apresentam (ao menos) uma das propriedades indesejáveis.

O efeito de gueto é o inverso exato do efeito de clube: enquanto o bairro chique, funcionando como um clube fundado na exclusão ativa das pessoas indesejáveis, consagra simbolicamente cada um de seus habitantes permitindo-lhe participar do capital acumulado pelo conjunto dos residentes, o gueto degrada simbolicamente seus habitantes, ajuntando em uma espécie de reserva um conjunto de agentes que, estando privados de todos os trunfos necessários para participar dos diferentes jogos sociais, só partilham de sua comum excomunicação. Além do efeito de estigmatização, o ajuntamento, em um mesmo lugar, de uma população homogênea na despossessão tem também por efeito redobrar a despossessão, notadamente em termos de cultura e de prática cultural (assim como, inversamente, ele reforça a prática cultural dos mais abastados).

Dentre todas as propriedades que a ocupação legítima de um lugar pressupõe, há aquelas - e não são as menos determinantes - que só se adquire pela ocupação prolongada desse lugar e a frequentação contínua de seus ocupantes 
legítimos: este é o caso, evidentemente, do capital social de relações (e muito particularmente, dessas relações privilegiadas que são as amizades de infância ou de adolescência), ou de todos os aspectos mais sutis do capital cultural e linguístico, como as maneiras corporais e os sotaques etc. É o conjunto dos traços que conferem todo o seu peso ao lugar de nascimento (e, em menor grau, ao lugar de residência).

Para mostrar como o poder e, em particular, o poder sobre o espaço conferido pela posse do capital sob suas diversas espécies, se retraduz no espaço físico apropriado sob a forma de uma distribuição espacial das posses ou das oportunidades de acesso aos bens e serviços raros, privados ou públicos, comecei a reunir há alguns anos, juntamente com Monique de Saint Martin, ${ }^{16}$ o conjunto dos dados estatísticos disponíveis, na escala de cada um dos departamentos franceses, ${ }^{17}$ tanto sobre os índices de capital econômico, cultural ou mesmo social, como sobre os bens e serviços oferecidos nessa escala. O objetivo do empreendimento era tentar apreender tudo o que - naquilo que se imputa frequentemente a efeitos de espaço físico ou geográfico, por uma submissão inconsciente ao efeito de naturalização, que opera a transformação do espaço social em espaço físico apropriado - pode e deve ser imputado, na realidade, ao efeito da estrutura da distribuição espacial dos recursos e dos bens, privados ou públicos, a qual não é, ela mesma, senão a cristalização, em um momento dado do tempo, de toda a história da unidade na base local considerada (região, departamento etc.), de sua posição no espaço nacional etc. Ainda que não se tenha podido finalizar o empreendimento por falta de tempo, ele ao menos permitiu concluir que o essencial das diferenças regionais que se imputam frequentemente ao efeito de determinismos geográficos (na lógica, por exemplo, da oposição entre "o Norte e o Sul" da França), deve a sua permanência na história ao efeito de reforço circular exercido continuamente ao longo da mesma história: pelo fato de as aspirações, notadamente em termos de habitat e, mais geralmente, de cultura, serem em grande parte o produto da estrutura da distribuição de bens e serviços no espaço físico apropriado, elas tendem a variar, assim como a capacidade de satisfazê-las, de modo que o efeito da distribuição desigual das aspirações acaba por redobrar, a cada momento, o efeito da distribuição desigual dos meios e das oportunidades de satisfazê-las.

Tendo identificado e medido o conjunto dos fenômenos que, embora aparentemente ligados ao espaço físico, refletem de fato diferenças econômicas e sociais, restaria tentar isolar o resíduo irredutível que deveria ser imputado exclusivamente ao efeito da proximidade e da distância no espaço puramente físico. Penso, por exemplo, no efeito de blindagem ${ }^{18}$ que resulta da localização em um ponto do espaço físico, e do privilégio antropológico que pertence ao presente diretamente percebido; e, ao mesmo tempo, penso no espaço visível e sensível dos objetos e dos agentes copresentes, dos vizinhos e da vizinhança: pode-se observar, assim, que hostilidades relativas à proximidade no espaço fí- 
sico (conflitos de vizinhança, por exemplo) podem ocultar solidariedades associadas à posição ocupada no espaço social nacional ou internacional; ou, ainda, que representações impostas pelo ponto de vista associado à posição ocupada no espaço social local (a aldeia, por exemplo) podem interditar a apreensão da posição efetivamente ocupada no espaço social nacional.

Notas

1 Comunicação apresentada no Colóquio "Poverty, Immigration and Urban Marginality in Advanced Societies", realizado na Maison Suger, da Maison des Sciences de l'Homme em 10-11 de maio de 1991, e complementada por anotações manuscritas do próprio Bourdieu e visíveis no original. A autoria das anotações foi atestada à Organizadora do dossiê "O espaço na vida social" por Marie-Christine Rivière, que foi assistente de Bourdieu e é atualmente responsável por seus arquivos, via e-mail de 10.4.2013. A Organizadora agradece a Dominique Vidal, Sergio Miceli e Bernd Schwibs o apoio em relação ao projeto desta publicação; e à Sra. Rivière, a presteza tanto em colaborar com o projeto e por autorizar a tradução e publicação deste texto em Estudos Avançados. E é grata em especial a Rainer Domschke por cruciais sugestões de revisão linguística. (N.O.)

2 No original, "place", termo bastante polissêmico, passível de ser também traduzido por "posição". Aqui, "place" constará como "local", no intuito de respeitar a distinção explícita que Bourdieu faz, no texto, entre "place" e "position". (N.R.)

3 No original, "encombrement". (N.R.)

4 Elucidativa a esse respeito é em particular a troca de correspondência entre o filósofo alemão Gottfied Wilhelm Leibniz (1646-1716) e o teólogo inglês newtoniano Samuel Clarke (1675-1729) em Samuel Clarke, A collection of papers which passed between the late learned Mr. Leibniz and Dr. Clarke in the years 1715/1716 relating to the principles of natural philosophy and religion, de 1717, publicada mais recentemente em alemão por Volkmar Schüller em Der Leibniz-Clarke Briefwechsel(Berlin: Akademie), de 1991. (N.R.)

5 No original francês, "sansfeu ni lieu". (N. R.)

6 Cf. a esse respeito em português Pierre Bourdieu, "A casa kabyle ou o mundo às avessas [1969]", trad. Claude Papavero, Cadernos de Campo, n.8, p.147-59, 1999. (N.R.)

7 No original, "foyer". (N.R.)

8 No original, "foyer des valeurs culturelles", levando-se em conta que em francês "foyer" tem também a acepção figurada de "foco", isto é, "ponto de convergência", "centro", remetendo a etimologia latina do termo "foco" a "lume", "fogão", "fogo". Cf. de Maurice Halbwachs, La classe ouvrière et les niveaux de vie, de 1913. (N.R.)

9 Cf. a respeito de Percy Ernst Schramm Die Geschichte des englischen Köngitums m Lichte der Krönung (Weimar: Böhlau), de 1937. (N.R.)

10 Cf. a respeito Pierre Bourdieu, A Distinção, trad. Daniela Kern e Guilherme J. F. Teixeira; rev. técn. Alexandre Dias Ramos, Daniela Kern e Ocadi Luiz Coradini. São Paulo: Zouk; Edusp, 2007. (N.R.) 
11 No original, respectivamente "riantes perspectives" e "Town and Country", termos que diferem daqueles usados no livro referido por Bourdieu, na verdade The Country and The City, de Raymond Williams (London; Reading; Fakenham: Paladin, 1973). Nessa obra, o escritor galês alude, no sentido evocado por Bourdieu, a "pleasing prospects", que foi vertido para o português como "vistas agradáveis". Cf. a respeito Raymond Williams, O campo e a cidade. Trad. Paulo Henriques Brito. São Paulo: Companhia das Letras, 2011, p.167ss. (N.R.)

12 Circunscrição administrativa que divide a capital francesa em subprefeituras. (N. T.)

13 No original, “bidonville”. (N.R.)

14 Trata-se de um conjunto de habitações de aluguel moderado, designado pela sigla HLM, que corresponde a Habitations à Loyer Modéré. (N.T.)

15 É a denominação dada pelos parisienses ao Centre Georges Pompidou, museu de arte moderna e contemporânea de Paris. (N.T.)

16 Socióloga e atualmente diretora honorária de estudos da École des Hautes Études en Sciences Sociales, Monique de Saint Martin era, à época de redação deste texto, codiretora do Centre de Sociologie de l'Éducation et de la Culture (entre 1985 e 1995), fundado por Bourdieu em 1968 (Disponível em: <http://iris.ehess.fr/document. php?id=740 >; acesso em: 11 ago. 2013. (N.R.)

17 No original, "départements français", divisões administrativas que constituem o segundo nível de divisão territorial da França depois das "regiões administrativas", que agrupam os "departamentos". (N.R.)

18 No original, "effet d'écran", expressão que comporta, como uma das possibilidades de tradução, "tela de projeção" (de televisão, de cinema etc.), tela de "proteção", de "blindagem", como a dos diafragmas das câmeras fotográficas. Considerando a imagem de acepção perspectivística construída por Bourdieu, que, aliás, reaparece na tradução alemã do texto, optou-se por "blindagem". (N.T.R.)

RESUMO - Concebido para um colóquio na Maison Suger e publicado apenas em alemão, antes de sair, agora, em português, este paper, pleno de revisões à mão por Pierre Bourdieu, lhe serviu de base para a elaboração do capítulo "Effets de lieu [Efeitos de lugar]" publicado em La misère du monde em 1991 (em português em 1997). No texto, o autor explicita de maneira até então inédita a sua concepção dos vínculos que o espaço social, trabalhado por ele em toda a sua obra, nutriria com o espaço físico: o primeiro se "retraduz" no segundo sob a forma de um determinado arranjo distributivo de agentes e propriedades, o que tem consequências para a compreensão da gênese da estrutura do "espaço físico apropriado", também por ele denominado "espaço social reificado".

PALAVRAS-CHAVE: Espaço físico, Espaço social, Espaço físico apropriado (espaço social reificado), Lugar (efeito de), Alocação.

ABSTRACT - Conceived for a conference at the Maison Suger, and plain of Pierre Bourdieu's own hand-written review notes, this paper has only by now been published in German and in Portuguese. It became the basis of the chapter "Effets de lieu [Effects of place]", which was published in La misère du monde in 1991 (and in Portuguese in 1997). In this text the author explains in a previously inedited way his conception on 
the links between social space - a constant issue in his work - and the physical space: the former "retranslates" itself in the latter in the form of a specific distributive arrangement of agents and properties. This concept has consequences for comprehending the genesis of the structure of the so-called "appropriated physical space", which he also calls "reified social space".

KEYWORDS: Physical space, Social space, Appropriated physical space (reified social space), Place (effects of), Emplacement.

Pierre Bourdieu (1930-2002), sociólogo francês, foi professor da École Pratique des Hautes Études entre 1964 e 1984, tornando-se, a partir de 1982, titular da Cátedra de Sociologia do Collège de France.

Tradução de Ana Cristina Arantes Nasser. Revisão técnica de Fraya Frehse. O original em francês - Espace physique, espace social et espace physique approprié - encontra-se à disposição do leitor no IEA-USP para eventual consulta.

Recebido em 23.9.2013 e aceito em 5.10.2013. 